\title{
Global risk of radioactive fallout after major nuclear reactor accidents
}

\author{
J. Lelieveld ${ }^{1,2}$, D. Kunkel ${ }^{1}$, and M. G. Lawrence ${ }^{1, *}$ \\ ${ }^{1}$ Max Planck Institute for Chemistry, P.O. Box 3060, 55020 Mainz, Germany \\ ${ }^{2}$ The Cyprus Institute, Nicosia, Cyprus \\ * now at: The Institute for Advanced Sustainability Studies, Potsdam, Germany
}

Correspondence to: J. Lelieveld (jos.lelieveld@mpic.de)

Received: 7 October 2011 - Published in Atmos. Chem. Phys. Discuss.: 25 November 2011

Revised: 24 April 2012 - Accepted: 27 April 2012 - Published: 12 May 2012

\begin{abstract}
Major reactor accidents of nuclear power plants are rare, yet the consequences are catastrophic. But what is meant by "rare"? And what can be learned from the Chernobyl and Fukushima incidents? Here we assess the cumulative, global risk of exposure to radioactivity due to atmospheric dispersion of gases and particles following severe nuclear accidents (the most severe ones on the International Nuclear Event Scale, INES 7), using particulate ${ }^{137} \mathrm{Cs}$ and gaseous ${ }^{131} \mathrm{I}$ as proxies for the fallout. Our results indicate that previously the occurrence of INES 7 major accidents and the risks of radioactive contamination have been underestimated. Using a global model of the atmosphere we compute that on average, in the event of a major reactor accident of any nuclear power plant worldwide, more than $90 \%$ of emitted ${ }^{137} \mathrm{Cs}$ would be transported beyond $50 \mathrm{~km}$ and about $50 \%$ beyond $1000 \mathrm{~km}$ distance before being deposited. This corroborates that such accidents have large-scale and transboundary impacts. Although the emission strengths and atmospheric removal processes of ${ }^{137} \mathrm{Cs}$ and ${ }^{131} \mathrm{I}$ are quite different, the radioactive contamination patterns over land and the human exposure due to deposition are computed to be similar. High human exposure risks occur around reactors in densely populated regions, notably in West Europe and South Asia, where a major reactor accident can subject around 30 million people to radioactive contamination. The recent decision by Germany to phase out its nuclear reactors will reduce the national risk, though a large risk will still remain from the reactors in neighbouring countries.
\end{abstract}

\section{Introduction}

Nuclear accidents associated with the melting of the reactor core are caused by the failure of the cooling systems, and can have major environmental and societal consequences. In total about 20 core melt events have occurred in military and commercial reactors worldwide since the early 1950s (Burns et al., 2012). An accident risk assessment of nuclear power plants (NPPs) by the US Nuclear Regulatory Commission in 1975 estimated the probability of a core melt at 1 in 20000 per year for a single reactor unit (NRC, 1975). A follow-up report in 1990 adjusted this number and indicated that the core damage frequency is not a value that can be calculated with certainty, though an appendix presented the following likelihood of a catastrophic accident (NRC, 1990):
a. Probability of core melt 1 in 10000 per year;
b. Probability of containment failure 1 in 100;
c. Probability of unfavourable wind direction 1 in 10 ;
d. Probability of meteorological inversion 1 in 10;
e. Probability of evacuation failure 1 in 10 .

The product of these possibilities is 1 in 1 billion per year for a single reactor (this assumes that factors (a)-(e) are independent, which is not the case, so that the actual risk of a catastrophic accident should be higher than this). Given this, with a total of about 440 active civilian reactors worldwide (IAEA, 2011; Supplement), and an estimated mean remaining lifetime of $20-25 \mathrm{yr}$ (together $\sim 10000$ reactor years), then the probability of such a major accident occurring in 
this period would be roughly 1 in 100000 . In light of the uncertainties, the simplicity of this calculation is appealing.

However, based on the evidence over the past decades one may conclude that the combined probabilities (a) and (b) have been underestimated. Furthermore, by using a state-ofthe-art global atmospheric model we can directly compute the anticipated dispersion of radionuclides, avoiding the need to guess the factors (c) and (d). In doing so, we find that the vast majority of the radioactivity is transported outside an area of $50 \mathrm{~km}$ radius, which can undermine evacuation measures, especially if concentrated deposition occurs at much greater distances from the accident, as was the case for Chernobyl in May 1986. Furthermore, even if an evacuation is successful in terms of saving human lives, large areas around the reactors are made uninhabitable for decades afterwards. Therefore, we argue that such events are catastrophic irrespective of evacuation failure or success, and exclude the factor (e).

To gain an overview of the geographical and populationweighted risk of contamination, we present calculations of the amount of radioactive fallout expected to occur within various distances around each reactor (mapping probabilistic fields of nuclear reactor risk sites; see Baklanov and Mahura, 2004). We address the most severe NPP disasters, defined as level 7 major accidents on the International Nuclear Event Scale (INES). Consequently, this excludes partial nuclear meltdowns that can possibly be contained, including for example the Three Mile Island accident in 1979, which was categorized as an INES level 5 accident. Since we cannot predict the radioactivity that would actually be released by future events, which depends on many factors such as reactor type, capacity and fuel (and burn-up of the fuel), we focus on the relative amount that would occur for any major accident. To at least provide an approximation of the absolute amount of radioactivity released, we use analyses of the welldocumented Chernobyl reactor accident as a proxy (Smith and Beresford, 2005; IAEA, 2006), and scale the emissions of other reactors worldwide according to their gross capacity to account for the different amounts of nuclear fuel involved. In the discussion we also address preliminary estimates of the Fukushima emissions of radioactivity and their implications for our risk assessment.

\section{The Chernobyl accident}

Radioactivity from the Chernobyl nuclear reactor incident, which occurred on 26 April 1986, impacted the entire Northern Hemisphere. In fact, the Chernobyl accident was not triggered by a typical core melt but rather by a strong power excursion, leading to an explosion that destroyed the reactor core. Anspaugh et al. (1988) estimated that the collective dose to humans was about 930000 Gray (the dose of ionizing radiation, expressed by $1 \mathrm{~Gy}$, is equivalent to $1 \mathrm{Siev}$ ert (Sv) for gamma and beta radiation, which represents the absorption of 1 Joule by one $\mathrm{kg}$ of matter). Nuclear accidents release both gaseous and particulate radioisotopes. The total radionuclide release of Chernobyl was influenced by the ignition of the graphite-moderated reactor, and amounted to $>12000 \mathrm{PBq}\left(\right.$ IAEA, 2006) $\left(\mathrm{P}\right.$ is peta $\left.=10^{15}\right)($ Table 1$)$. The on-going fires released a large amount of fuel particles ("hot" particles) carrying isotopes of cerium, zirconium, molybdenum, neptunium and plutonium (Smith and Beresford, 2005; IAEA, 2006). These particles were relatively large and quickly sedimented from the atmosphere, primarily contaminating an area of about $30 \mathrm{~km}$ around the reactor.

Since the Chernobyl type reactor technology is now considered obsolete, we rather focus on the radionuclides that were emitted as gases and attached to ambient aerosol particles, e.g., the semi-volatile isotopes of iodine, strontium, caesium, tellurium, ruthenium and barium $\left({ }^{131,133} \mathrm{I},{ }^{89,90} \mathrm{Sr}\right.$, ${ }^{134,137} \mathrm{Cs},{ }^{132} \mathrm{Te},{ }^{103,106} \mathrm{Ru}$ and $\left.{ }^{140} \mathrm{Ba}\right)$. These radionuclides were mostly found on small particles with a radius of $r \leq$ $1 \mu \mathrm{m}$, which deposit slowly by gravitational settling and are more effectively removed by rainfall, usually further downwind than the large particles. For a review of measured size distributions of radioactive aerosols we refer to Dorrian (1997).

Although only a small fraction of the radionuclides from the Chernobyl accident was released as ${ }^{137} \mathrm{Cs}$, i.e., $85 \mathrm{PBq}$ (about $27 \mathrm{~kg}$ ), ${ }^{137} \mathrm{Cs}$ (half-life of $30 \mathrm{yr}$ ) is used to map the deposition because it is straightforward to measure and is radiologically important on a long time scale (Smith and Beresford, 2005; IAEA, 2006). ${ }^{131}$ I (half-life of 8 days), of which Chernobyl emitted about $1760 \mathrm{PBq}$, is also important; especially in the first weeks after an accident, as it is released in relatively large quantities, leading to high doses, because it rapidly enters the food chain and is concentrated in the thyroid (IAEA, 2006; WHO, 2006; Christodouleas et al., 2011). To put the emissions by Chernobyl into perspective, we list in Table 1 the known level 4 to 7 accidents and their estimated radioactivity release to the atmosphere, partly based on non-official information gathered from the Internet (http://de.wikipedia.org/wiki/Liste_der_Kernkraftwerke, http://en.wikipedia.org/wiki/List_of_nuclear_reactors, http:// www.iaea.org/programmes/a2/ and references therein).

Since there is little reliable information besides Chernobyl about the release and even less about the deposition of radionuclides from a catastrophic accident, we apply the Chernobyl data in our model to give a first approximation, and simulate that a major accident of each reactor similarly releases a fraction of $85 \mathrm{PBq}$ of ${ }^{137} \mathrm{Cs}$ and $1760 \mathrm{PBq}$ of ${ }^{131} \mathrm{I}$, depending on the amount of reactor fuel, over a period of one year. For each reactor we scaled the emissions to its gross capacity (relative to that of Chernobyl) to approximately account for the differences in fuel that could be involved in a meltdown. Thus a reactor with half the gross capacity of Chernobyl is assumed to emit half of the amount mentioned above. 
Table 1. Radioactivity released to the atmosphere by INES 4-7 nuclear accidents (in PBq).

\begin{tabular}{llcllll}
\hline Location & Country & INES & Date & Total & ${ }^{131}$ I & ${ }^{137}$ Cs \\
\hline Fukushima & Japan & 7 & 11 March 2011 & $>630$ & $190-380$ & $12-37$ \\
Chernobyl & USSR & 7 & 26 April 1986 & $>12000$ & 1760 & 85 \\
Mayak & USSR & 6 & 29 September 1957 & $74-1850$ & n.d.a & n.d.a \\
Chalk River & Canada & 5 & 12 December 1952 & $>0.3$ & n.d.a. & n.d.a. \\
Windscale & UK & 5 & 10 October 1957 & 1.6 & 0.7 & 0.02 \\
Simi Valley & USA & $5-6$ & 26 July 1959 & $>200^{\text {a }}$ & b & n.d.a. \\
Belojarsk & USSR & 5 & 1977 & n.d.a. & n.d.a. & n.d.a. \\
Three Mile Island & USA & 5 & 28 March 1979 & $1.6^{c}$ & $<0.0007$ & n.d.a. \\
Chernobyl & USSR & 5 & 1 September 1982 & n.d.a. & n.d.a. & n.d.a. \\
Idaho Falls & USA & 4 & 29 November 1955 & d & d & d \\
Idaho Falls & USA & 4 & 3 January 1961 & n.d.a. & n.d.a. & n.d.a. \\
Monroe & USA & 4 & 5 October 1966 & d & d & d \\
Lucens & Switzerland & $4-5$ & 21 January 1969 & d & d & d \\
Windscale & UK & 4 & 1973 & n.d.a. & n.d.a. & n.d.a. \\
Leningrad & USSR & $4-5$ & 6 February 1974 & e & n.d.a. & n.d.a. \\
Leningrad & USSR & $4-5$ & October 1974 & 55 & n.d.a. & n.d.a. \\
Jaslovské Bohunice & CSSR & 4 & 22 February 1977 & n.d.a. & n.d.a. & n.d.a. \\
Saint-Laurent & France & 4 & 13 March 1980 & n.d.a. & n.d.a. & n.d.a. \\
Buenos Aires & Argentina & 4 & 23 September 1983 & n.d.a. & b & n.d.a. \\
Tokaimura & Japan & 4 & 30 September 1999 & n.d.a. & n.d.a. & n.d.a. \\
\hline
\end{tabular}

INES $0-3$ events are indicated as deviations, anomalies and incidents;

INES 4 is an accident with local consequences; INES 5 is an accident with wider consequences;

INES 6 is a serious accident; INES 7 is a major accident (major release of radioactive material with widespread health and environmental effects requiring implementation of planned and extended countermeasures);

n.d.a. no data available; ${ }^{\text {a }}$ Substantial emissions of ${ }^{85} \mathrm{Kr},{ }^{133} \mathrm{Xe}$ assumed though n.d.a.; ${ }^{\mathrm{b}}$ Substantial ${ }^{131} \mathrm{I}$ emissions assumed, though

n.d.a.; ${ }^{\mathrm{c}}$ Mainly ${ }^{85} \mathrm{Kr}$ emitted; ${ }^{\mathrm{d}}$ No strong source of radioactivity to the atmosphere; ${ }^{\mathrm{e}}$ Release of radioactive sludge from filter

powder to the environment.

By integrating over a year we capture the annual range of meteorological conditions, thus providing a stochastic representation of the atmospheric transport and deposition pathways, accounting for the different seasons. During an actual accident the total deposition likely occurs over a much shorter time period, as was the case with the Chernobyl reactor. To assess the effect of individual accidents one would need to simulate the actual emissions and meteorological conditions in a deterministic approach (http://flexrisk. boku.ac.at/). Such calculations can be performed when the emissions and meteorological conditions are known, which has been done for Chernobyl and needs to be done for Fukushima. For our risk calculations the total deposition over all meteorological conditions is relevant, rather than the actual time period of any individual accident. For this reason we assess the contamination risk per year in Sect. 4. To illustrate the intra-annual variability, we also present monthly contamination risk maps in Sect. 4 by assuming that the same emission occurs within one month rather than one year. Furthermore, in Sect. 6 we test our approach by comparing the continuous annual simulations with those in which we release the radioactivity in weekly periods for two selected locations.

\section{Global model calculations}

Simulations of particulate ${ }^{137} \mathrm{Cs}$ and gaseous ${ }^{131} \mathrm{I}$ have been performed with the ECHAM5/MESSy Atmospheric Chemistry (EMAC) general circulation model (Roeckner et al., 2006; Jöckel et al., 2006; Kerkweg et al., 2006, 2007; Tost et al., 2007; Burrows et al., 2009; Pringle et al., 2010). The model has been extensively evaluated against observations, including satellite measurements (Kerkweg et al., 2008; Liu et al., 2011; Pozzer et al., 2010, 2012). We applied it at T106 horizontal resolution (corresponding to a quadratic Gaussian grid of about $1.1 \times 1.1^{\circ}$ in longitude and latitude, roughly $100 \times 100 \mathrm{~km}$ ) and 31 vertical layers up to $10 \mathrm{hPa}$. The emissions of all NPPs are represented by separate ${ }^{137} \mathrm{Cs}$ and ${ }^{131} \mathrm{I}$ tracers. The applied sub-models, which simulate all relevant meteorological processes for the dispersion of the aerosols, are: CLOUD, CONVECT, RAD4ALL, PTRAC, CVTRANS, ONLEM, DRYDEP, SEDI, SCAV (for a description, see http://www.messy-interface.org/). For a similar application, using the EMAC model at T106 resolution to represent a series of point sources (i.e., major population centres worldwide), see Kunkel et al. (2012). We simulated the year 2005, which we consider representative, i.e., without strong annular modes (e.g., El Niño, North Atlantic Oscillation), by using meteorological analyses from the European 
Centre for Medium-range Forecasts (ECMWF) to nudge the general circulation model (Lelieveld et al., 2007). It will be interesting to also study the effects of annual modes on the transport of radioactivity in future work.

To test the representativeness of the year 2005 we performed multi-year tracer tests for a sub-set of the tracers, and find that the transport patterns and deposition fields are not significantly sensitive to this assumption. We simulated $1.5 \mathrm{yr}$ in total, starting in 2004. The model setup has been designed such that first the airborne tracer mass is in steady state (which takes about 3-4 months). Therefore, the first six months are used for spin-up and the last twelve for the analysis. At the beginning of our analysis there is already tracer mass present in the atmosphere, which is consequently deposited within the analysis period and is about the same as the tracer mass that is still airborne at the end of the analysis period.

The mean aerosol lifetime of ${ }^{137} \mathrm{Cs}$ in the atmosphere, about one week, is much shorter than the decay time of the radionuclei; therefore the removal of particulate radioactivity is controlled by wet and dry deposition of the particles, rather than atmospheric decay. ${ }^{131} \mathrm{I}$ has a much shorter halflife, so that a significant amount can decay radioactively before depositional loss; we assume that it travels in the gas phase as ${ }^{131} \mathrm{I}_{2}$ and have represented its dry deposition using the method of Ganzeveld et al. (1998), based on the concept of Wesely (1989). We apply a Henry's law coefficient of $3.1 \mathrm{moll}^{-1} \mathrm{~atm}^{-1}$, indicating a low solubility. For a review of deposition modelling methods we refer to Sportisse (2007). A small fraction of the ${ }^{131} \mathrm{I}$ may be incorporated in other gases than $\mathrm{I}_{2}$ and in aerosols, and we thus implicitly assume that their deposition processes are the same.

In the model we emit the ${ }^{137} \mathrm{Cs}$ on aerosol particles with a mean radius of $0.5 \mu \mathrm{m}$ by introducing them into the surface layer of about $60 \mathrm{~m}$ depth. We assume that ${ }^{131} \mathrm{I}$ and ${ }^{137} \mathrm{Cs}$ are released gradually at the surface and not explosively or by large fires, which would increase the effective emission height (Chernobyl burned during 10 days). This would be particularly important when the effective emission height exceeds that of the well-mixed boundary layer (typically 1$3 \mathrm{~km}$ ). Regarding the sensitivity that could be expected to explosive versus gradual emissions, two dimensions need to be considered. Temporally, we have demonstrated that the average deposition from the continuous emissions is comparable to the expected value of short-term emissions occurring during any week of the year. Spatially, we can refer to Pozzer et al. (2009), who applied our model to compare air pollution emissions released from the surface and according to a height profile, the latter being relevant for emissions by biomass burning and from high stacks. The results indicate that the impact on atmospheric chemistry is generally small, typically less than $5 \%$ in the free troposphere and less than $30 \%$ in polluted regions. Since we neglect elevated sources, our estimates of long-distance transport should be considered as conservative (see also Kunkel et al., 2012).
Since the chemical composition of the particles is not known, we adopted two categories, one "soluble" and one "insoluble", which represent the extremes of possible particle characteristics. The main difference between the two is that only soluble particles are removed by nucleation scavenging, i.e., they can act as cloud condensation nuclei $(\mathrm{CCN})$, though do not exert feedbacks on cloud formation processes. Both soluble and insoluble particles are removed by impaction scavenging (Tost et al., 2007), aerosol sedimentation and dry deposition (Kerkweg et al., 2006). Thus, the insoluble particles have a longer lifetime due to reduced wet deposition and the consequently extended transport in the atmosphere. The difference between the results from the two simulations is typically less than $30 \%$.

To test these assumptions and the model setup, we simulated the Chernobyl accident in 1986 to study the distribution of ${ }^{137} \mathrm{Cs}$ deposition and compare it with a compilationinterpolation of measurement data presented by Smith and Beresford (2005), based on the original work of De Cort et al. (1998). The source profile of ${ }^{137} \mathrm{Cs}$, including the emission height, has been adopted from Brandt et al. (2002), based on several publications. Since the deposition data could not be made available from the Radioactivity Environmental Monitoring (REM) Action of the European Commission, we evaluated the model output by comparing with a deposition map based on all available data (Smith and Beresford, 2005; Peplow, 2006), applying the same colour scaling in Fig. 1. We find that that our results agree well with the map of Peplow (2006) (see also IAEA, 2006), especially of our soluble tracer, indicating ${ }^{137} \mathrm{Cs}$ deposition in excess of $40 \mathrm{kBq} \mathrm{m}^{-2}$ in the Ukraine, Scandinavia, Northern Greece, southern Germany and Austria (Fig. 1).

This qualitative agreement is quite satisfactory, especially because quantitative agreement cannot be expected due to the neglect of the large particles emitted by Chernobyl fires and the difficulty of accurately simulating the emission time and height profiles. Considering that we achieve the best agreement with the soluble tracer, and since the majority of particles acts as CCN (Pruppacher and Klett, 1997), we henceforth assume that $75 \%$ of the aerosol is removed by nucleation scavenging (75\% soluble and $25 \%$ insoluble particles). Our total ${ }^{137} \mathrm{Cs}$ deposition distribution also compares favourably with the high-resolution regional model results of Brandt et al. (2002), notably the map for which the most sophisticated deposition method was applied (their Fig. 7).

Subsequently we emitted gaseous ${ }^{131}$ I and particulate ${ }^{137} \mathrm{Cs}$ from each of the 440 active reactors worldwide for the year 2005 (the reactors, locations and operational lifetimes are listed in the Supplement). The calculations indicate that on average only about $8 \%$ of the ${ }^{137} \mathrm{Cs}$ deposits within $50 \mathrm{~km}$ of the source, $\sim 30 \%$ within $500 \mathrm{~km}, \sim 50 \%$ within $1000 \mathrm{~km}$, and that about $25 \%$ is transported beyond $2000 \mathrm{~km}$. Clearly, radionuclides from a reactor accident anywhere in the world would not only be deposited locally. The variability of these fractions for different regions, e.g., in Europe, the 

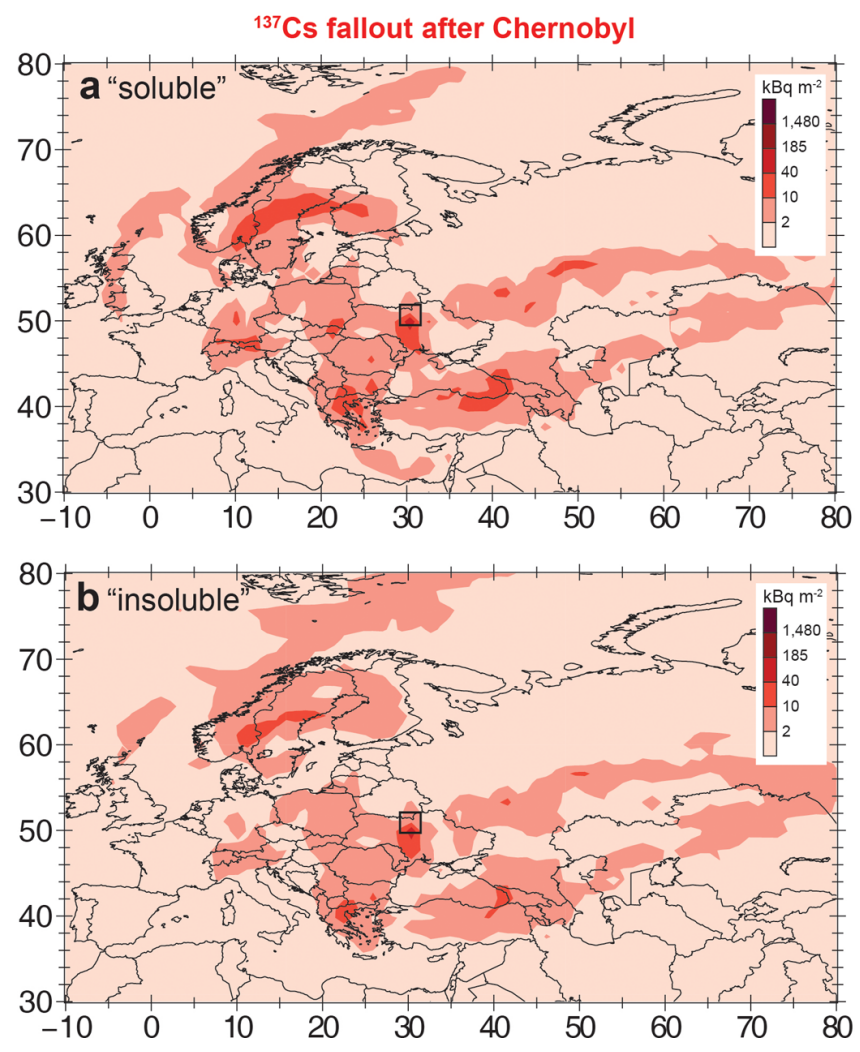

Fig. 1. Model calculated fallout of ${ }^{137} \mathrm{Cs}$ after the Chernobyl accident, assuming a soluble particle tracer (a) and an insoluble one (b). The location of Chernobyl is indicated by the black square. The colour scale is the same as in Peplow (2006); see http://www.nature. com/nature/journal/v440/n7087/full/440982a.html.

USA and Asia is relatively small, even though the retention of emissions near the surface in temperate and high latitudes is typically stronger than in the tropics where the intensity of convection is greater (Lawrence et al., 2007). Risks for human exposure in regions with NPPs are much more variable, largely determined by population densities, and for individual major accidents they are highest in South Asia and West Europe, and lowest in North Europe.

\section{Deposition risk assessment}

To evaluate the global risks, we can use empirical evidence to estimate the factors (a) and (b) from above. In the past decades, four INES level 7 catastrophic nuclear meltdowns have occurred, one in Chernobyl and three in Fukushima. Note again that we are not considering INES 6 and lower level accidents with partial core melts such as Three Mile Island (USA), Mayak (a plutonium production and reprocessing plant in Siberia) and Sellafield (UK). The total number of operational reactor years since the first civilian nuclear power station in Obninsk (1954) until 2011 has been about 14500 (IAEA, 2011; Supplement). This suggests that the probabil- ity of a major reactor accident, i.e., the combined probability of the factors (a) and (b), is much higher than estimated in 1990.

Simply taking the four reactor meltdowns over the 14500 reactor years would indicate a probability of 1 in 3625 per reactor per year, 275 times larger than the 1990 estimate (NRC, 1990). However, since 2011 is at a junction in time with impacts of a catastrophic meltdown still unfolding, this direct estimate is high-biased, and we round it off to 1 in 5000 per reactor per year for use in our model simulations. This is actually only a factor of two higher than the estimated core melt probability noted above, factor (a), although originally this factor also represented partial core melts, which have occurred more frequently. Based on the past evidence, this principally assumes that if a major accident occurs, the probability of containment before substantial radioactivity release is very small. We thus argue that including the factors (b)-(e) can distort the risk perception. Our rounded estimate implies that with 440 civilian reactors worldwide a major accident can be expected to occur about once every few decades, depending on whether we count Fukushima as a triple or a single event.

Although an objective measure for dangerous radioactive contamination is debatable, a level of $>37 \mathrm{kBq}^{137} \mathrm{Cs} \mathrm{m}^{-2}$ or $\geq 40 \mathrm{kBq} \mathrm{m}^{-2}$ for beta- and gamma-emitters has been suggested after the Chernobyl accident as a threshold contamination level (IAEA, 2005, 2006). The reasons given by IAEA (2006) are that:

- This level was about ten times higher than the ${ }^{137} \mathrm{Cs}$ deposition in Europe from global fallout;

- At this level the human dose during the first year after the major accident was about $1 \mathrm{mSv}$ and was considered to be radiologically important.

Here we define $\geq 40 \mathrm{kBqm}^{-2}$ as "contaminated", following the definition by IAEA (2005). Subsequently, the risk of contamination has been calculated based on the expression: (modelled total ${ }^{137} \mathrm{Cs}$ deposition $\left.\left(\mathrm{kBq} \mathrm{m}^{-2} \mathrm{yr}^{-1}\right) / 40 \mathrm{kBq} \mathrm{m}^{-2}\right) \times($ probability of a major accident). Hence the presented risk maps correspond directly to the model calculated ${ }^{137} \mathrm{Cs}$ deposition distribution.

Figure 2a shows the modelled annual risks of contamination, from lower than $0.01 \% \mathrm{yr}^{-1}$ in Alaska and eastern Canada, much of Africa and Australia, to higher than $2 \% \mathrm{yr}^{-1}$ in some areas around multiple reactors in the northeastern USA, West Europe and Japan. These numbers signify the expected values, defined as the weighted average (first moment) of an independent variable of all possible values it can take. The weights correspond to the probabilities of these values. This means, for example, that on average in the Northeast USA, West Europe and Japan contamination by major accidents is expected at least every $50 \mathrm{yr}$, which is in accord with the frequency of past events in Europe and Japan. In Fig. 3 we present regionally enhanced sub-sections 

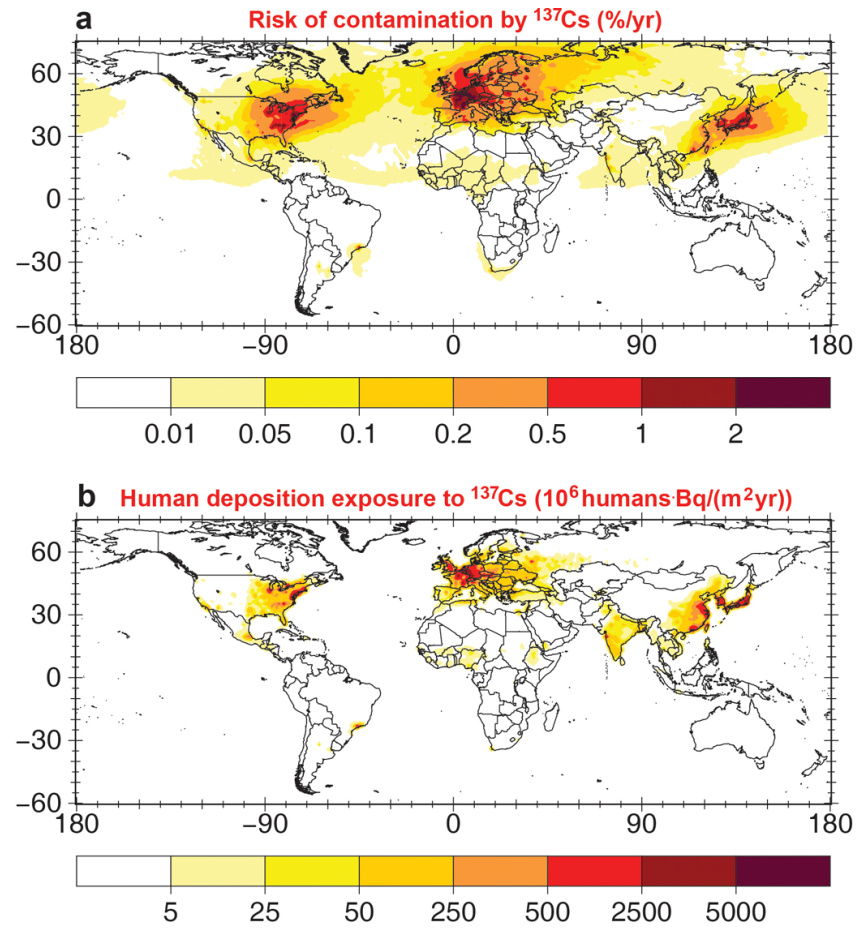

Fig. 2. Global risk of radioactive contamination by ${ }^{137} \mathrm{Cs}$. (a) Based on the modelled deposition of $\geq 40 \mathrm{kBq}{ }^{137} \mathrm{Cs} \mathrm{m}^{-2} \mathrm{yr}^{-1}$. The risk is the expected value normalized by $40 \mathrm{kBq} \mathrm{m}^{-2}$. (b) Modelled risk of human exposure to ${ }^{137} \mathrm{Cs}$ deposition.

of the same depiction as Fig. 2. There are extended regions with a risk of $>1 \% \mathrm{yr}^{-1}$, and large parts of North America, East Asia and especially Europe have risks of more than $1 \% \mathrm{yr}^{-1}$, as indicated by the orange colour scale. In Fig. $2 \mathrm{~b}$ and the lower panels of Fig. 3 we weigh the expected deposition with population density (SEDAC, 2011), which underscores the disproportional risk of contamination for people in regions with many reactors in Europe, parts of the USA and Asia.

Figures 4 and 5 show the results for ${ }^{131}$ I, again defining $\geq 40 \mathrm{kBq} \mathrm{m}^{-2}$ as "contaminated". Interestingly, the deposition patterns over land and the risks of contamination and human exposure are quite comparable to ${ }^{137} \mathrm{Cs}$. Even though the amount of radioactivity released by Chernobyl as ${ }^{131} \mathrm{I}$ was $\sim 20$ times that of ${ }^{137} \mathrm{Cs}$, the low solubility of iodine and its $\sim 1400$ times shorter half-life limit the deposition, especially on water surfaces. Recall that ${ }^{131} \mathrm{I}$ and ${ }^{137} \mathrm{Cs}$ are used as proxies for the total release and deposition of radionuclides, also including ${ }^{90} \mathrm{Sr}$ and ${ }^{134} \mathrm{Cs}$, for example. By adding the risks of the two tracers in Figs. 2 and 4, the total risk of contamination by $\geq 40 \mathrm{kBq} \mathrm{m}^{-2}$ is roughly twice that indicated by the individual contamination risks. Furthermore, the risks scale with the addition of other tracers such as ${ }^{134} \mathrm{Cs}$ and ${ }^{90} \mathrm{Sr}$. However, also recall that we have taken the emissions by Chernobyl, scaled by gross reactor capacity, as a proxy for all 440 civilian reactors. Preliminary es- timates of the release of radioactivity during the first three weeks after the Fukushima accident are substantially lower than for Chernobyl, i.e., $\sim 140 \mathrm{PBq}$ of ${ }^{131} \mathrm{I}$ and $\sim 10 \mathrm{PBq}$ of ${ }^{137} \mathrm{Cs}$ (Chino et al., 2011). Winiarek et al. (2012) estimated that the ${ }^{137} \mathrm{Cs}$ and ${ }^{131} \mathrm{I}$ releases by Fukushima were about a factor of 5-10 less than of Chernobyl. Stohl et al. (2012) calculated that during a period of 40 days after the accident $\sim 37 \mathrm{PBq}$ of ${ }^{137} \mathrm{Cs}$ were released, about $43 \%$ of the emission by Chernobyl. If the latter would be more representative of accidents associated with core melts than Chernobyl, the numbers in Figs. 2-5 would decrease by about a factor of seven. Since these are only preliminary values, not including the full time period of release and only apply to one single radionuclide, it seems likely that these estimates bound the actual probabilities.

It is important to underscore the different effects of ${ }^{131} \mathrm{I}$ and ${ }^{137} \mathrm{Cs}$. In the initial period after accidents ${ }^{131} \mathrm{I}$ is of greatest concern as it deposits on agricultural crops, contaminating fruits, herbs and vegetables, and on grasslands where dairy cows graze (IAEA, 2006; Christodouleas et al., 2011). The contaminated grass ingested by the cows is transferred to the milk in about a day (Beresford et al., 2000). Even though the half-life of ${ }^{131} \mathrm{I}$ is only 8 days, it may elevate longterm cancer risks (Christodouleas et al., 2011). According to Figs. 2-5 the integrated deposition loads of ${ }^{131} \mathrm{I}$ and ${ }^{137} \mathrm{Cs}$ are similar, while the latter exerts long-term effects through its cycling and re-suspension in soils, groundwater and the vegetation. The half-life of ${ }^{137} \mathrm{Cs}$ (and ${ }^{134} \mathrm{Cs}$ and ${ }^{90} \mathrm{Sr}$ ) is years to decades, and the main problem is the enduring exposure of the fauna through forage and humans through meat, milk and to a lesser extent vegetables (IAEA, 2006; WHO, 2006).

We emphasize that our results represent a probabilistic assessment that is representative for an entire year and integrate the accumulated deposition over the annual range of weather conditions, thus accounting for the temporal and spatial variability of transport and removal processes (Baklanov and Mahura, 2004). However, Chernobyl and Fukushima have demonstrated that most of the radioactivity emissions occur within the first month after the accident. To demonstrate the difference between the annually and monthly integrated risks of contamination by ${ }^{137} \mathrm{Cs}$ we also performed simulations that condense the same release of radioactivity within single months (Fig. 6). Hence the total deposition during each month in Fig. 6 is approximately the same as in Fig. 2, but the distribution differs depending on the meteorological conditions specific to the month of release.

The monthly deposition patterns in Fig. 6 are similar to the annual ones though differ in specific aspects. In most locations downwind of NPPs in the Northern Hemisphere - notably at middle latitudes - the risks are highest in late spring and summer; in continental Europe in May and July, for example. The risk of contamination in the USA, Europe and Japan is generally lowest in the winter. In Japan it is highest from June to September and in East Canada during late summer and autumn (November). The westerly outflow from 

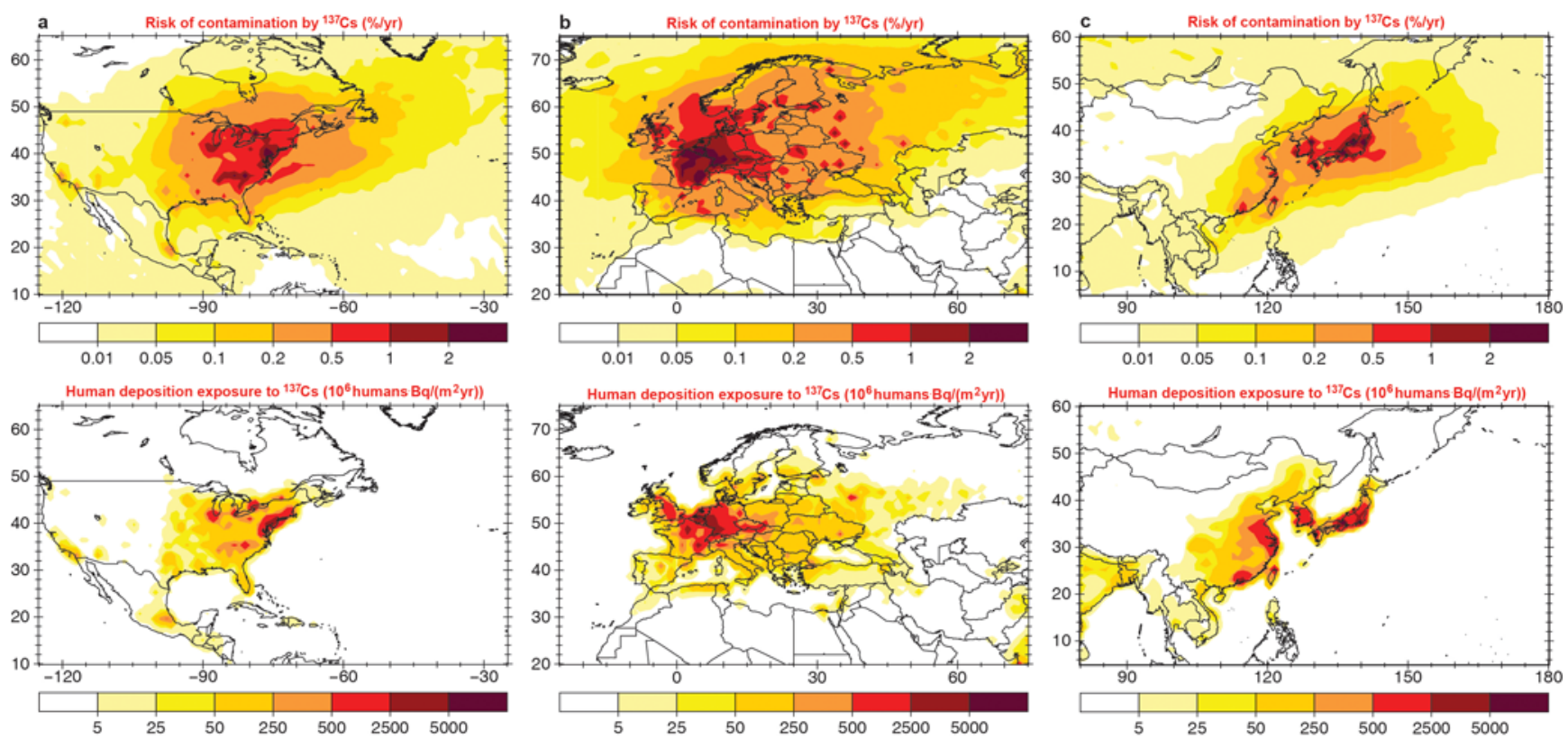

Fig. 3. Regional risks of radioactive contamination by ${ }^{137}$ Cs. Same as Fig. 2 for selected regions.

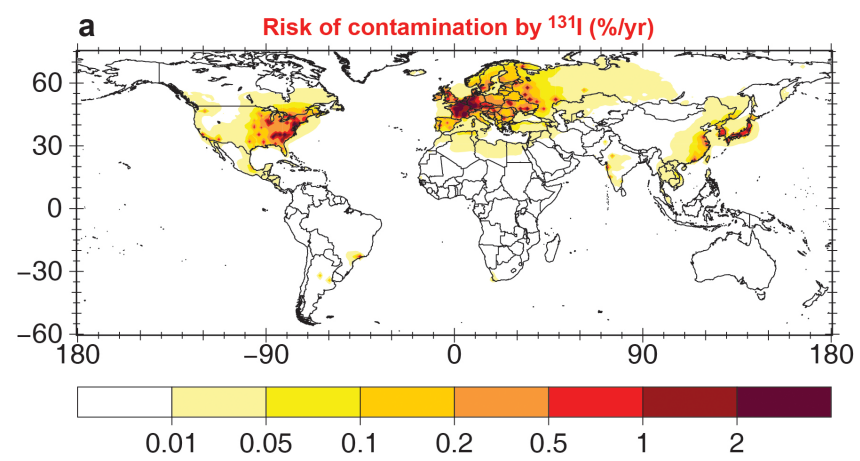

\section{Footprint of catastrophic accidents}

Next we calculated the footprint of major nuclear accidents and find that the average surface area onto which $\geq 40 \mathrm{kBq}^{137} \mathrm{Cs} \mathrm{m}^{-2}$ would be deposited in regions around a reactor after a catastrophic core melt is on average about $138000 \mathrm{~km}^{2}$ with a typical range of $\pm 20 \%$. The area that is estimated to be at risk of contamination by a single accident is largest in West Europe, about $165000 \mathrm{~km}^{2}$, while in East Asia it is $153000 \mathrm{~km}^{2}$, followed by East USA with $148000 \mathrm{~km}^{2}, 140000$ in Midwest USA, $129000 \mathrm{~km}^{2}$ in North Europe and $102000 \mathrm{~km}^{2}$ in South Asia.

b Human deposition exposure to ${ }^{131} \mathrm{I}\left(10^{6}\right.$ humans $\left.\mathrm{Bq} /\left(\mathrm{m}^{2} \mathrm{yr}\right)\right)$

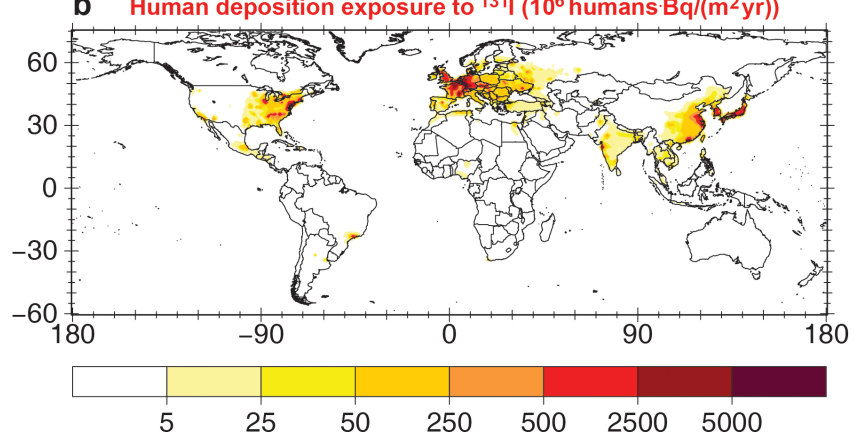

Fig. 4. Global risk of radioactive contamination by ${ }^{131}$ I. (a) Modelled deposition of $\geq 40 \mathrm{kBq}^{131} \mathrm{I} \mathrm{m}^{-2} \mathrm{yr}^{-1}$. The risk is the expected value normalized by $40 \mathrm{kBq} \mathrm{m}^{-2}$. (b) Modelled risk of human exposure to ${ }^{131} \mathrm{I}$ deposition.

North America and East Asia is strongest from December to March, diverting the risks to the Atlantic and Pacific Oceans, respectively, while transport from Europe to the Arctic region and across Russia is strongest in winter and early spring.

Much of the variability is related to the strength of vertical transport in convective storms and removal by precipitation, for example during the monsoon. This is consistent with the findings of Lawrence et al. (2007), who showed that the venting of pollutants from the boundary layer is generally strongest in the tropics (e.g., in South Asia), whereas in the extra-tropics, where most NPPs are located, the radionuclides will tend to remain more in the boundary layer over longer near-surface transport distances. Our model results indicate that the average number of people that would be affected by the radioactive contamination of ${ }^{137} \mathrm{Cs}$ due to a single reactor accident varies strongly by region: about $3 \mathrm{M}$ in North Europe, $8 \mathrm{M}$ in the Midwest USA, $8 \mathrm{M}$ in East Europe, $14 \mathrm{M}$ in East USA, $21 \mathrm{M}$ in East Asia, $28 \mathrm{M}$ in West Europe, and $34 \mathrm{M}$ in South Asia ( $\mathrm{M}$ is mega $=10^{6}$ ).

For Chernobyl we computed a ${ }^{137} \mathrm{Cs}$-contaminated area of about $113000 \mathrm{~km}^{2}$, endangering about 8 million people (note that this refers to 2005 mean meteorology and population statistics, not the 1986 simulation). This is not far from the published estimate for the Chernobyl accident, suggesting 

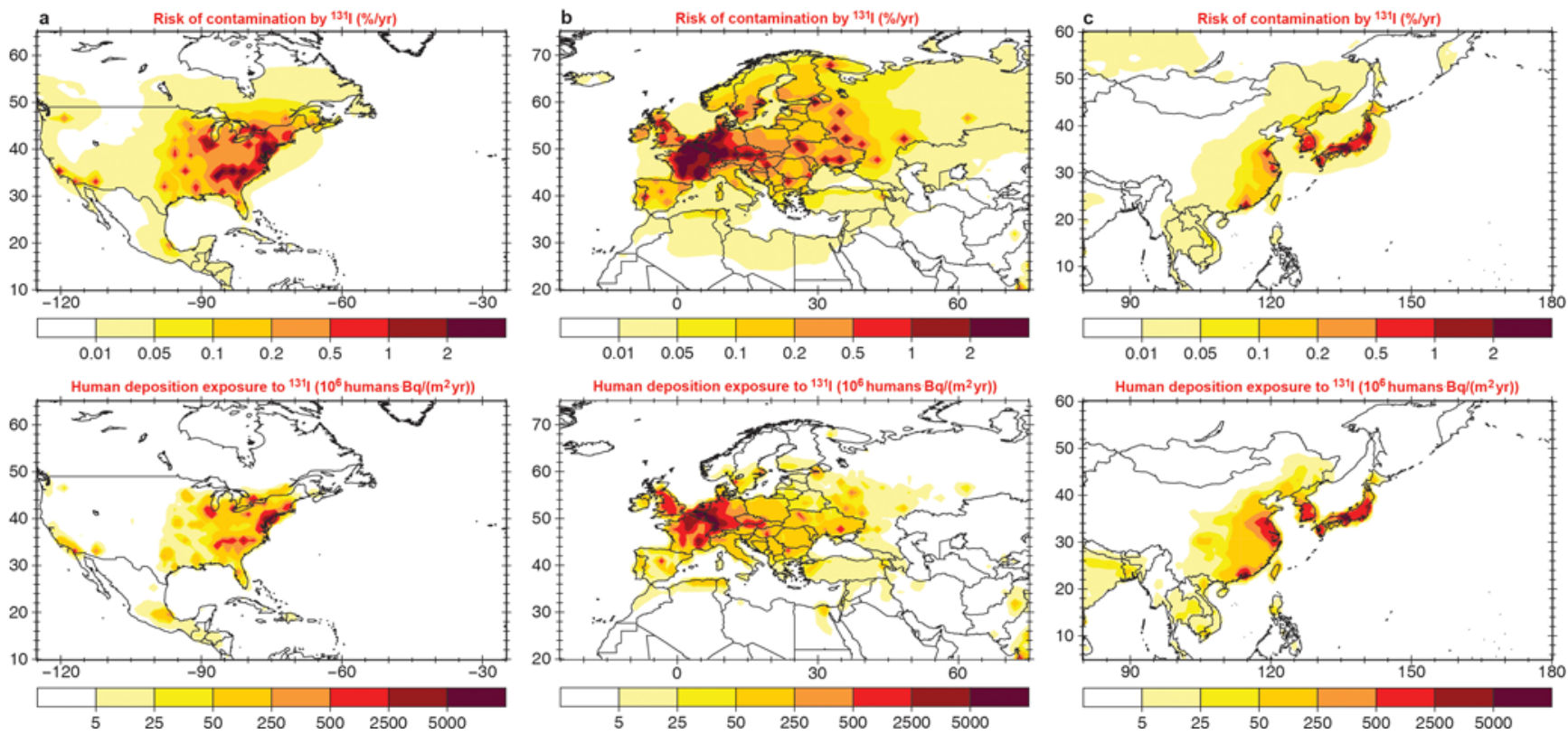

Fig. 5. Regional risks of radioactive contamination by ${ }^{131}$ I. Same as Fig. 4 for selected regions.

that an area of about $200000 \mathrm{~km}^{2}$ was contaminated, affecting more than 5 million people (Smith and Beresford, 2005), which provides additional support for the validity of our approach and its representativeness for other time periods. The model calculations suggest that some regions have a particularly high risk of contamination, due to the numerous reactors in operation, for example the region between Washington D.C. and New York, and around Atlanta, Toronto, Tokyo and Osaka. Many regions are densely populated and associated with a high human exposure risk, for example also the Shanghai region and Hong Kong. The highest risk of radioactive contamination occurs in West Europe, especially around the borders between Germany, Belgium and France, with the greatest human exposure risk in southwestern Germany in the area between Stuttgart and Cologne.

\section{Sensitivity to short-term and annual emissions}

In our global model simulations we have assumed a continuous source of radioactivity throughout the year 2005 from each of the 440 reactors, from which we calculated the fallout and subsequently the risk of contamination, thus accounting for the annual range of meteorological conditions. In Sect. 4 and Fig. 6 we also presented results of monthly simulations for comparison. One might argue that employing a continuous source does not lead to the same result as a more realistic simulation of a short-term emission of radioactivity, since Chernobyl and Fukushima released most radioactivity within weeks (see the interactive discussion of the ACPD version of our manuscript: http://www.atmos-chem-phys-discuss.net/ 11/31207/2011/acpd-11-31207-2011-discussion.html).
To further test the sensitivity to this assumption we have performed additional model calculations in which we released the same amount of radioactivity within one week, during each of the 52 weeks of the year, from two locations: Chernobyl and Fukushima. For both source locations we obtain deposition fields for each weekly release which are integrated between the beginning of 2005 and end of March 2006. Then we calculate a mean deposition field of these 52 single deposition fields to compare with the deposition from the continuous annual emissions.

Figure 7 depicts the total atmospheric load of ${ }^{137} \mathrm{Cs}$ resulting from each of the weekly emission events, showing that most of the aerosol-borne reactivity is removed within about a month. The longest aerosol lifetimes and largest atmospheric loads occur in periods when rain events downwind are relatively infrequent, e.g., for Chernobyl in early spring (April) and autumn (September). For Fukushima the variability is generally less, with a minimum atmospheric load (i.e., most efficient removal) in summer (July-August). The maximum atmospheric loads per week from Chernobyl are typically larger $\left(\sim 20-70 \mathrm{PBq}{ }^{137} \mathrm{Cs}\right)$ than from the same emission in Fukushima $\left(\sim 10-40 \mathrm{PBq}{ }^{137} \mathrm{Cs}\right)$, indicating that atmospheric removal of the aerosol-borne radioactivity is generally more efficient for Fukushima.

Figures 8 and 9 compare the ${ }^{137} \mathrm{Cs}$ fallout patterns of the weekly and annual emission simulations. The differences (i.e., annual - weekly deposition) are generally small, especially in the region around Chernobyl where they are typically within $\pm 10 \%$, which corroborates the validity of our approach. In the Fukushima area they are somewhat larger, and the annual emission calculations lead to slightly higher 

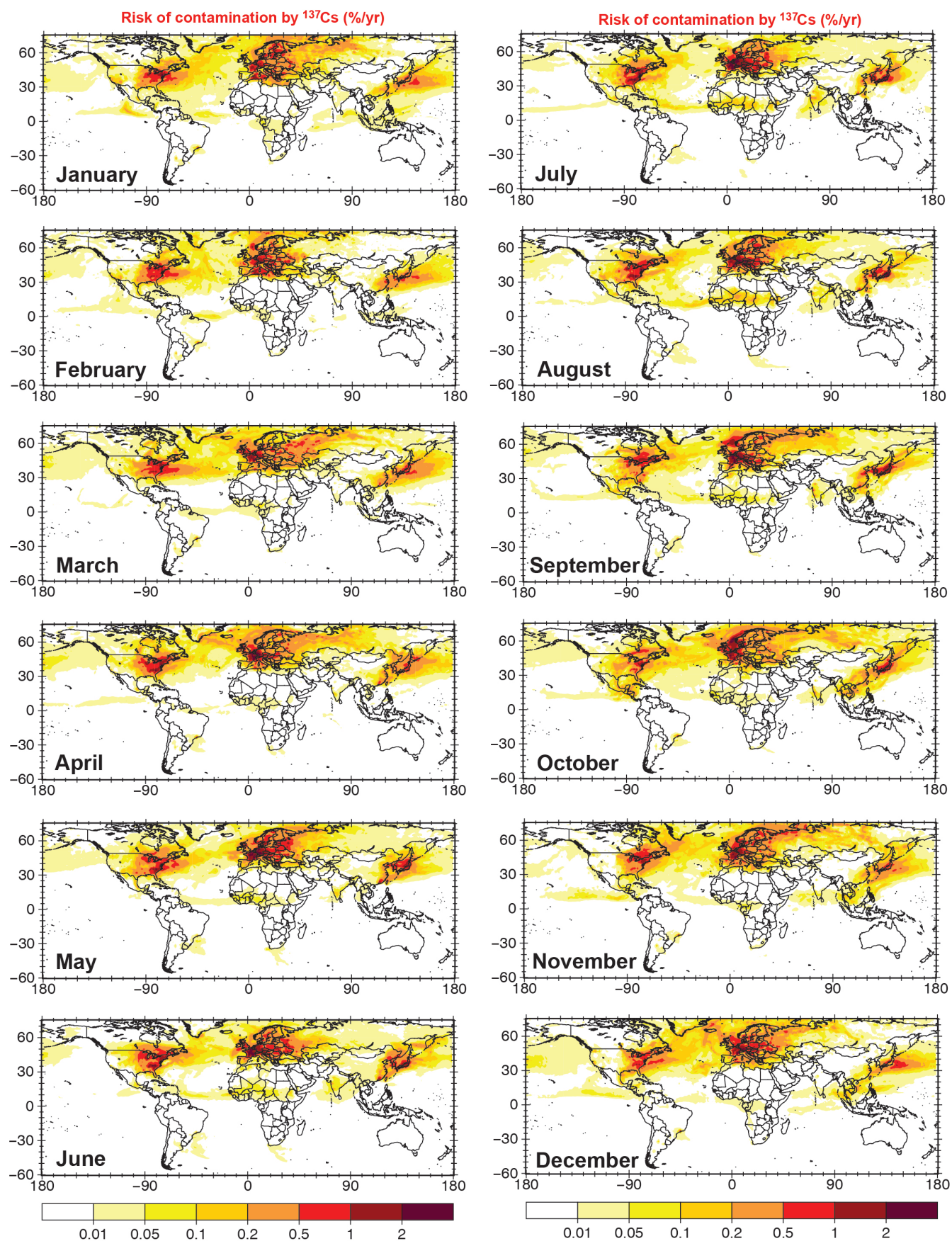

Fig. 6. Global risk of radioactive contamination by ${ }^{137} \mathrm{Cs}$ based on the modelled deposition of $\geq 40 \mathrm{kBq}{ }^{137} \mathrm{Cs} \mathrm{m}^{-2} / \mathrm{month}$, applying the same emission as in Fig. 2 though monthly instead of annually.

${ }^{137}$ Cs fallout in the Pacific Rim vicinity of the reactor (i.e., the domain shown in Fig. 9). It thus appears that our stochastic approach is appropriate, though possibly leading to conservative estimates of the contamination impact after severe reactor accidents.

\section{Phase-out of NPPs in Germany}

In the wake of the events in Fukushima the German government has decided to phase out all nuclear power plants over the next decade (in accord with the theory that large-impact and rare events are leading causes of societal change; see Taleb, 2010). Figure 10a presents calculations in which the 17 German reactors have been switched off. This reduces the 


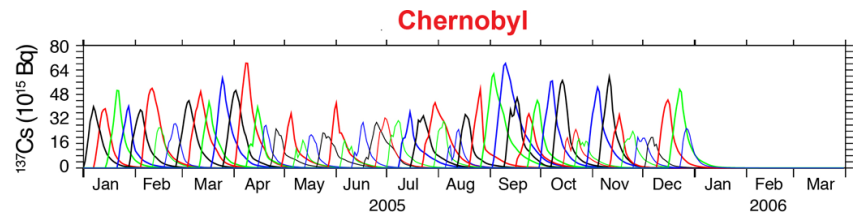

Fukushima

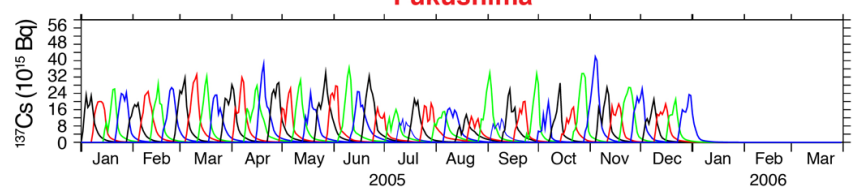

Fig. 7. Atmospheric load of ${ }^{137} \mathrm{Cs}$ by applying the emissions of Chernobyl $(85 \mathrm{pBq})$ each week. The simulations were performed for the locations of Chernobyl and Fukushima, applying the same source term.

expected ${ }^{137} \mathrm{Cs}$ deposition in Germany by about a factor of two, though it nevertheless continues to be among the highest worldwide. Only in France (58 reactors) and Belgium (7 reactors) does the overall risk remain higher. Figure 10b shows that by switching off the reactors in neighbouring countries, i.e., France, Belgium, the Netherlands, Switzerland and the Czech Republic, but leaving all 17 German reactors active, the deposition risk in Germany would be even more effectively reduced than by the national efforts alone. This emphasizes that, for the sake of reducing the risk of exposure to radioactivity, there is a need to coordinate phase-out decisions on an international level, especially when NPPs are located in the vicinity of international borders.

\section{Conclusions and recommendations}

Using our stochastic approach, it will be possible to evaluate other risks besides direct human exposure, including biological and indirect health risks. For instance, linking to agricultural information will allow evaluation of the risk that radioactivity enters the food chain. Clearly there is a need to perform an extensive re-assessment of the factors (a) and (b), discussed above, based on the evidence from Chernobyl, Fukushima and other less catastrophic accidents. In particular, a better understanding of reactor risk profiles and expected release of radioactivity in case of a meltdown is required. This depends on several aspects, including:

- Type of reactor and capacity;

- Reactor maintenance, safety culture and other human factors;

- Safety improvements with the progress of technology;

- Degradation of the concrete reactor shell with age;

- Enhanced risk for NPPs with multiple reactors and shared technical facilities;
- The likelihood of natural disasters such as earthquakes and tsunamis;

- Susceptibility to aircraft impacts, sabotage and terrorist attacks.

Key information in the assessment of exposure risks is the emission strength of radioactivity by major nuclear accidents. Table 1 illustrates that this information is generally poor or lacking, also for Fukushima (Taira and Hatoyama, 2011), except for Chernobyl. Therefore, we have used the available reports of the Chernobyl disaster - by scaling the emissions of the other reactors according to their gross capacity. It will be important to also evaluate the Fukushima accident with the same level of scrutiny as Chernobyl to complement the available data. In a future publication we will report simulation results from the Fukushima accident, which will be tested against radionuclide measurement data from the Comprehensive Nuclear-Test-Ban Treaty Organization (CTBTO). Preliminary estimates suggest that the Fukushima emissions of radioactivity are up to an order of magnitude less than of Chernobyl. If representative for NPPs, this would reduce the risks of contamination by ${ }^{137} \mathrm{Cs}$ presented here correspondingly and the present risk assessment may be considered as a worst-case scenario. However, since most of the radioactivity from Fukushima has been deposited to the Pacific Ocean, remote from measurement stations, the inverse computation of emissions based on observational data will be difficult, although the back-calculation of trans-Pacific transport based on measurements along the US west coast holds promise (Priyadarshi et al., 2011).

The transport and deposition calculations presented here may be regarded as "scalable" because the modelling of ${ }^{137} \mathrm{Cs}$ is a near-linear tracer experiment, as long as the tracer lifetime is significantly longer than the lifetime of the aerosols on which they travel and the statistics of the meteorological conditions are representative. For example, if $50 \%$ or $10 \%$ of the ${ }^{137} \mathrm{Cs}$ release by Chernobyl would be more representative for modern NPPs, the deposition and contamination risks could be scaled down by a factor of two or ten, respectively. On the other hand, if one wishes to account for additional radionuclides such as ${ }^{134} \mathrm{Cs}$ (the Chernobyl release of radioactivity by ${ }^{134} \mathrm{Cs}$ was about $50 \%$ of ${ }^{137} \mathrm{Cs}$ ) the ${ }^{137} \mathrm{Cs}$ results could be scaled up by a factor of 1.5 based on Chernobyl.

Furthermore, it will be important to re-think the level of "dangerous" contamination. We applied $40 \mathrm{kBq} \mathrm{m}^{-2}$ of ${ }^{137} \mathrm{Cs}$, but this does not do justice to the dangers by the short-lived ${ }^{131} \mathrm{I}$ and the additional contamination by other long-lived radionuclides. Since Chernobyl released many other beta- and gamma-emitters to which the contamination threshold of $40 \mathrm{kBq} \mathrm{m}^{-2}$ applies, including hot particles, we feel that using the Chernobyl emissions of ${ }^{137} \mathrm{Cs}$ is a reasonable compromise between the prospect that modern NPPs release less radioactivity and the use of reasonably accurate 

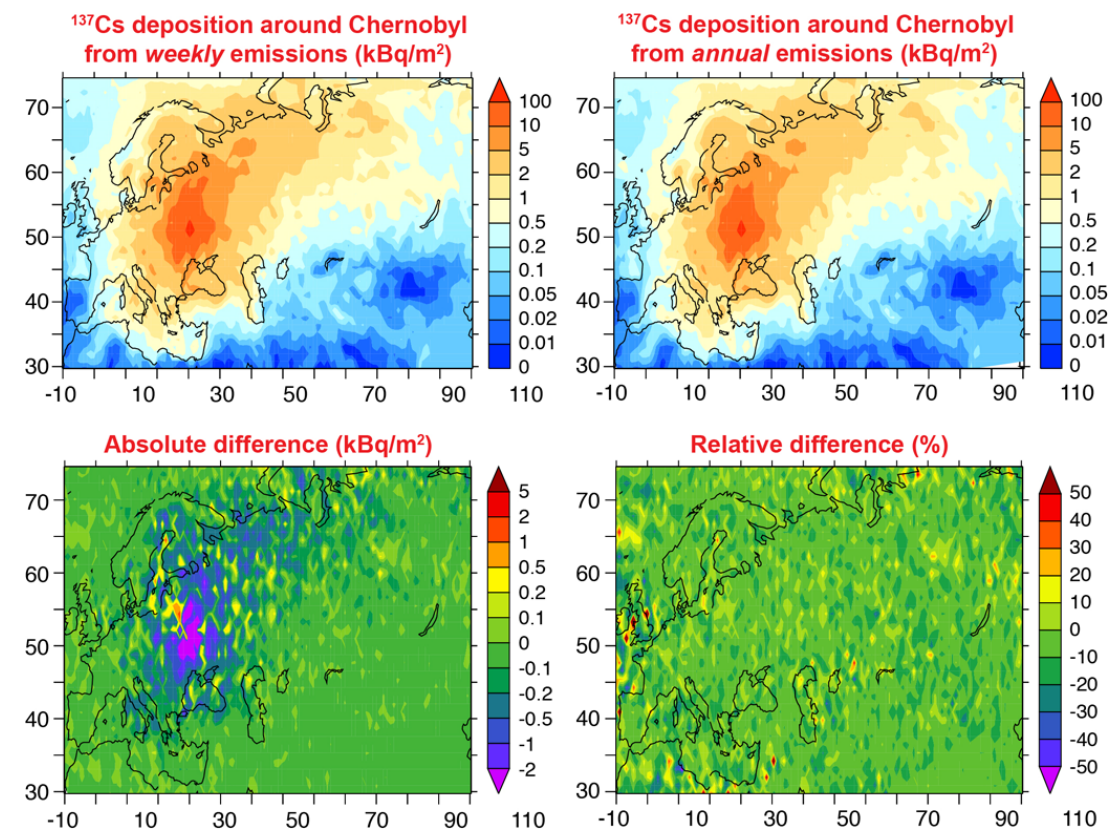

Fig. 8. Yearly-integrated fallout of ${ }^{137}$ Cs (year 2005), comparing annually continuous to weekly emissions (both the same total source strength of Chernobyl), released from the location of Chernobyl.
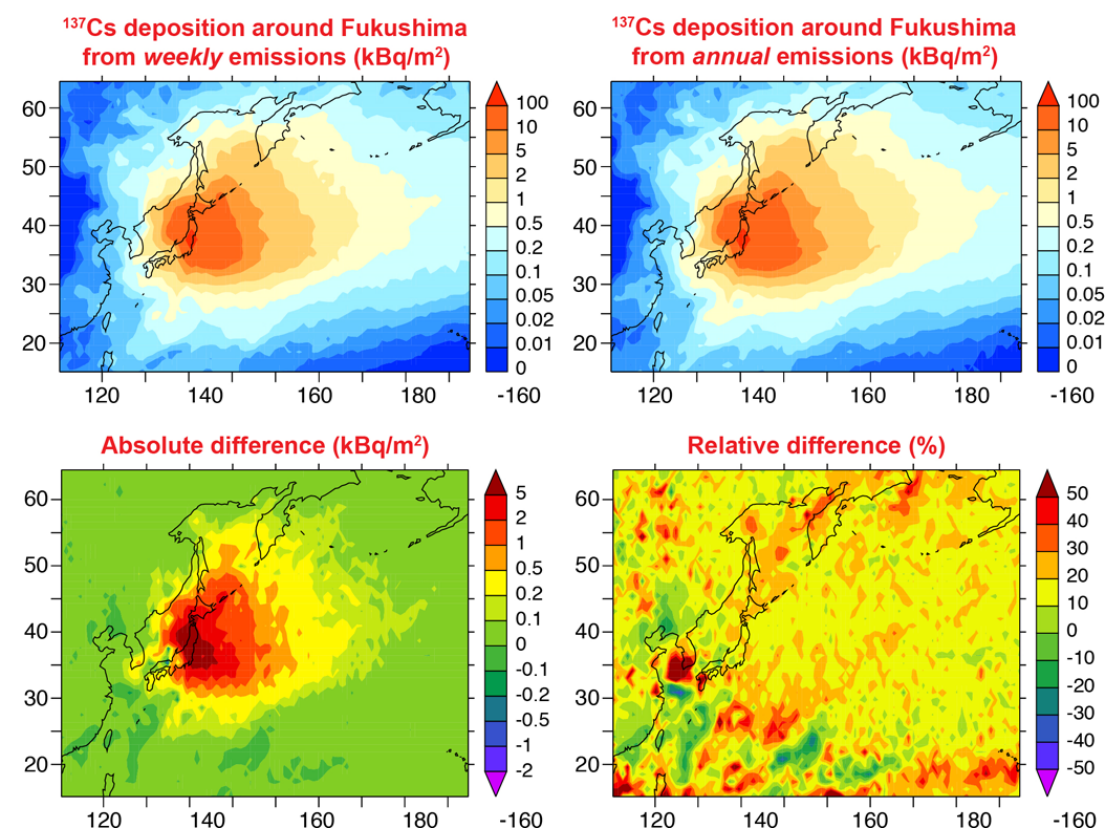

Fig. 9. Yearly-integrated fallout of ${ }^{137}$ Cs (year 2005), comparing annually continuous to weekly emissions (both the same total source strength of Chernobyl), released from the location of Fukushima.

emission estimates of ${ }^{137} \mathrm{Cs}$, even though they may represent an upper limit.

Going beyond the factors (a) and (b), the probabilities of a core melt and containment failure, we have provided a better understanding of the impact of atmospheric dispersion, providing evidence that the widespread risks to humanity of nuclear accidents are much larger than suggested in official reports several decades ago. Although improved risk assessments may have been performed for some reactors more recently, unfortunately their results and the basic assumptions about the release of radioactivity after major accidents are not 


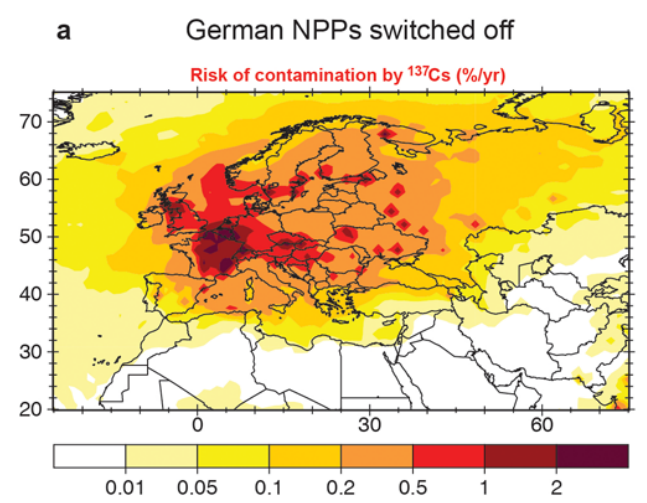

b NPPs of Germany's neigbours switched off
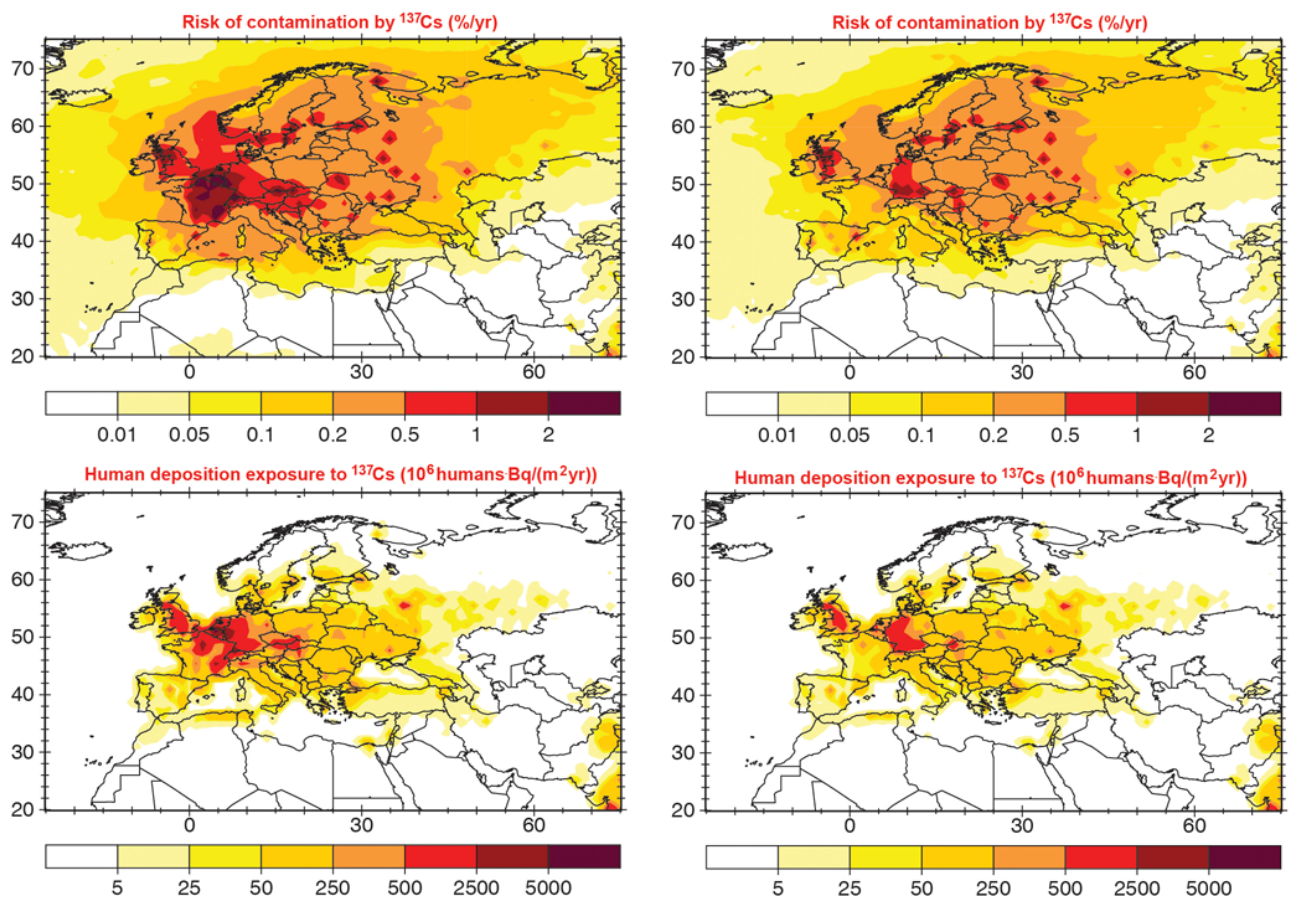

Fig. 10. Phasing out nuclear power plants. (a) Same as Fig. 3b, indicating the regional risks of contamination by ${ }^{137} \mathrm{Cs}$ with German reactors switched off. (b) Same as Fig. 3b with reactors in the neighbouring countries of Germany switched off (i.e., France, Belgium, the Netherlands, Switzerland and the Czech Republic).

publicly available. Publication in the peer-reviewed literature would help scientific scrutiny as well as the public debate.

It is important to select reactor sites by accounting for the proximity to large population centres, as there appears to be a tendency to build NPPs in the vicinity of electricity consumers in urban regions. NPPs in densely populated areas in Europe, the USA, eastern Asia and southern Asia bear a high risk of exposing large numbers of people to radioactive contamination after reactor accidents. In western Europe (notably France), the concentration of NPPs is relatively high, and although the phase out in Germany in the next decade will halve the national risk of radioactive contamination by major accidents, international efforts will be necessary to achieve the German safety objectives. Worldwide more than 60 reactors are currently under construction (Supplement) and many more are planned, hence the global risks may change accordingly in the coming years.

\section{Supplementary material related to this article is available online at: http://www.atmos-chem-phys.net/12/ 4245/2012/acp-12-4245-2012-supplement.pdf.}

Acknowledgements. We thank the anonymous contributors to Wikipedia for the list of nuclear power plants and information about radioactivity releases, Sarah Alznauer and Bettina Krüger for tabulation and editing help, and the Computing Centre (RZ) Garching (in particular Hermann Lederer) for computer support. We also thank Henning Rodhe, Falk Schmidt, Costas Papanicolas, Greet Maenhout and Paul Crutzen for comments and discussions. The research leading to these results has received funding from the European Research Council under the European Union's Seventh Framework Programme (FP7/2007-2013)/ERC grant agreement no 226144.

The service charges for this open access publication have been covered by the Max Planck Society.

Edited by: M. K. Dubey

\section{References}

Anspaugh, L. R., Catlin, R. J., and Goldman, M.: The global impact of the Chernobyl reactor accident, Science, 242, 1513-1519, 1988.

Baklanov, A. A. and Mahura, A. G.: Assessment of possible airborne impact from risk sites: methodology for probabilistic atmospheric studies, Atmos. Chem. Phys., 4, 485-495, doi:10.5194/acp-4-485-2004, 2004.

Beresford, N. A., Mayes, R. W., Cooke, A. I., Barnett, C. L., Howard, B. J., Lamb, C. S., and Naylor, G. P. L.: The importance of source-dependent bioavailability in determining the transfer of ingested radionuclides to ruminant-derived food products, Environ. Sci. Technol., 34, 4455-4462, 2000. 
Brandt, J., Christensen, J. H., and Frohn, L. M.: Modelling transport and deposition of caesium and iodine from the Chernobyl accident using the DREAM model, Atmos. Chem. Phys., 2, 397-417, doi:10.5194/acp-2-397-2002, 2002.

Burns, P. C., Ewing, R. C., and Navrotsky, A.: Nuclear fuel in a reactor accident, Science, 335, 1184-1188, 2012.

Burrows, S. M., Butler, T., Jöckel, P., Tost, H., Kerkweg, A., Pöschl, U., and Lawrence, M. G.: Bacteria in the global atmosphere - Part 2: Modeling of emissions and transport between different ecosystems, Atmos. Chem. Phys., 9, 9281-9297, doi:10.5194/acp-9-9281-2009, 2009.

Chino, M., Nakayama, H., Nagai, H., Terada, H., Katata, G., and Yamazawa, H.: Preliminary estimation of the release amounts of ${ }^{131} \mathrm{I}$ and ${ }^{137} \mathrm{Cs}$ accidentally discharged from the Fukushima Daiichi nuclear power plant into the atmosphere, J. Nucl. Sci. Technol., 48, 1129-1134, 2011.

Christodouleas, J. P., Forrest, R. D., Ainsley, C. G., Tochner, Z., Hahn, S. M., and Glatstein, E.: Short-term and long-term health risks of nuclear power plant accidents, New Eng. J. Med., 364, 2334-2341, 2011.

De Cort, M., Fridman, S. D., Izrael, Y. A., Joners, A. R., Kelly, G. N., Kvasnikova, E. V., Matveenko, I. I., Nazarov, I. M., Stukin, E. D., Tabachny, L. Y., and Tsaturov, Y. S.: Atlas of Caesium deposition on Europe after the Chernobyl accident, EUR 16733, EC, Office for Official Publications of the European Communities, Luxembourg, 1998.

Dorrian, M. D.: Particle size distributions of radioactive aerosols in the environment, Rad. Protect. Dos, 69, 117-132, 1997.

Ganzeveld, L., Lelieveld, J., and Roelofs, G.-J.: A dry deposition parameterization for sulfur oxides in a chemistry and general circulation model, J. Geophys. Res., 103, 5679-5694, 1998.

International Atomic Energy Agency (IAEA): Regulations for the safe transport of radioactive material, IAEA Safety Standards Series TS-R-1, Vienna, 2005.

International Atomic Energy Agency (IAEA): Environmental Consequences of the Chernobyl Accident and Their Remediation: Twenty Years of Experience, IAEA, Vienna, 2006.

International Atomic Energy Agency (IAEA): Nuclear power plants around the world, IAEA-RDS-2/31, Vienna, 2011.

Jöckel, P., Tost, H., Pozzer, A., Brühl, C., Buchholz, J., Ganzeveld, L., Hoor, P., Kerkweg, A., Lawrence, M. G., Sander, R., Steil, B., Stiller, G., Tanarhte, M., Taraborrelli, D., van Aardenne, J., and Lelieveld, J.: The atmospheric chemistry general circulation model ECHAM5/MESSy1: consistent simulation of ozone from the surface to the mesosphere, Atmos. Chem. Phys., 6, 50675104, doi:10.5194/acp-6-5067-2006, 2006.

Kerkweg, A., Buchholz, J., Ganzeveld, L., Pozzer, A., Tost, H., and Jöckel, P.: Technical Note: An implementation of the dry removal processes DRY DEPosition and SEDImentation in the Modular Earth Submodel System (MESSy), Atmos. Chem. Phys., 6, 4617-4632, doi:10.5194/acp-6-4617-2006, 2006.

Kerkweg, A., Sander, R., Tost, H., Jöckel, P., and Lelieveld, J.: Technical Note: Simulation of detailed aerosol chemistry on the global scale using MECCA-AERO, Atmos. Chem. Phys., 7, 2973-2985, doi:10.5194/acp-7-2973-2007, 2007.

Kerkweg, A., Jöckel, P., Pozzer, A., Tost, H., Sander, R., Schulz, M., Stier, P., Vignati, E., Wilson, J., and Lelieveld, J.: Consistent simulation of bromine chemistry from the marine boundary layer to the stratosphere - Part 1: Model description, sea salt aerosols and pH, Atmos. Chem. Phys., 8, 5899-5917, doi:10.5194/acp-85899-2008, 2008.

Kunkel, D., Lawrence, M. G., Tost, H., Kerkweg, A., Jöckel, P., and Borrmann, S.: Urban emission hot spots as sources for remote aerosol deposition, Geophys. Res. Lett., 39, L01808, doi:10.1029/2011GL049634, 2012.

Lawrence, M. G., Butler, T. M., Steinkamp, J., Gurjar, B. R., and Lelieveld, J.: Regional pollution potentials of megacities and other major population centers, Atmos. Chem. Phys., 7, 39693987, doi:10.5194/acp-7-3969-2007, 2007.

Lelieveld, J., Brühl, C., Jöckel, P., Steil, B., Crutzen, P. J., Fischer, H., Giorgetta, M. A., Hoor, P., Lawrence, M. G., Sausen, R., and Tost, H.: Stratospheric dryness: model simulations and satellite observations, Atmos. Chem. Phys., 7, 1313-1332, doi:10.5194/acp-7-1313-2007, 2007.

Liu, C., Beirle, S., Butler, T., Liu, J., Hoor, P., Jöckel, P., Penning de Vries, M., Pozzer, A., Frankenberg, C., Lawrence, M. G., Lelieveld, J., Platt, U., and Wagner, T.: Application of SCIAMACHY and MOPITT CO total column measurements to evaluate model results over biomass burning regions and Eastern China, Atmos. Chem. Phys., 11, 6083-6114, doi:10.5194/acp11-6083-2011, 2011.

Nuclear Regulatory Commission (NRC): Reactor Safety Study An Assessment of Accident Risk in U.S. Commercial Nuclear Power Plants, WASH-1400, NUREG 75/014, 1975.

Nuclear Regulatory Commission (NRC): Severe Accident Risks An Assessment for Five U.S. Nuclear Power Plants, NUREG 1150, 1990.

Peplow, M.: Counting the dead (special report about the death toll of the Chernobyl accident), Nature, 440, 982-983, 2006.

Pozzer, A., Jöckel, P., and Van Aardenne, J.: The influence of the vertical distribution of emissions on tropospheric chemistry, Atmos. Chem. Phys., 9, 9417-9432, doi:10.5194/acp-9-9417-2009, 2009.

Pozzer, A., Pollmann, J., Taraborrelli, D., Jöckel, P., Helmig, D., Tans, P., Hueber, J., and Lelieveld, J.: Observed and simulated global distribution and budget of atmospheric $\mathrm{C}_{2}-\mathrm{C}_{5}$ alkanes, Atmos. Chem. Phys., 10, 4403-4422, doi:10.5194/acp-10-44032010, 2010.

Pozzer, A., de Meij, A., Pringle, K. J., Tost, H., Doering, U. M., van Aardenne, J., and Lelieveld, J.: Distributions and regional budgets of aerosols and their precursors simulated with the EMAC chemistry-climate model, Atmos. Chem. Phys., 12, 961-987, doi:10.5194/acp-12-961-2012, 2012.

Pringle, K. J., Tost, H., Message, S., Steil, B., Giannadaki, D., Nenes, A., Fountoukis, C., Stier, P., Vignati, E., and Lelieveld, J.: Description and evaluation of GMXe: a new aerosol submodel for global simulations (v1), Geosci. Model Dev., 3, 391-412, doi:10.5194/gmd-3-391-2010, 2010.

Priyadarshi, A., Dominguez, G., and Thiemens, M. H.: Evidence of neutron leakage at the Fukushima nuclear plant from measurements of radioactive ${ }^{35} \mathrm{~S}$ in California, P. Natl. Acad. Sci., 108, 14422-14425, 2011.

Pruppacher, H. R. and Klett, J. D.: Microphysics of clouds and precipitation, Kluwer Academic Publishers, Dordrecht, 1997.

Roeckner, E., Brokopf, R., Esch, M., Giorgetta, M., Hagemann, S., Kornblüh, Manzini, L. E., Schlese, U., and Schulzweida, U.: Sensitivity of simulated climate to horizontal and vertical resolution in the ECHAM5 atmosphere model, J. Climate, 19, 3771-3791, 
2006.

Smith, J. T. and Beresford, N. A.: Chernobyl - Catastrophe and Consequences, Springer, Berlin, 2005.

Socioeconomic Data and Applications Center (SEDAC): Columbia University, available at: http://sedac.ciesin.columbia.edu/gpw, 2011.

Sportisse, B.: A review of parameterizations for modelling dry deposition and scavenging of radionuclides, Atmos. Environ., 41, 2683-2698, 2007.

Stohl, A., Seibert, P., Wotawa, G., Arnold, D., Burkhart, J. F., Eckhardt, S., Tapia, C., Vargas, A., and Yasunari, T. J.: Xenon133 and caesium-137 releases into the atmosphere from the Fukushima Dai-ichi nuclear power plant: determination of the source term, atmospheric dispersion, and deposition, Atmos. Chem. Phys., 12, 2313-2343, doi:10.5194/acp-12-2313-2012, 2012.

Taira, T. and Hatoyama, Y.: Nationalize the Fukushima Daiichi atomic plant, Nature, 480, 313-314, 2011.

Taleb, N. N.: The Black Swan: The impact of the highly improbable, Random House, 2010.
Tost, H., Jöckel, P., Kerkweg, A., Pozzer, A., Sander, R., and Lelieveld, J.: Global cloud and precipitation chemistry and wet deposition: tropospheric model simulations with ECHAM5/MESSy1, Atmos. Chem. Phys., 7, 2733-2757, doi:10.5194/acp-7-2733-2007, 2007.

Wesely, M. L.: Parameterization of surface resistance to gaseous dry deposition in regional scale numerical models, Atmos. Environ., 23, 1293-1304, 1989.

Winiarek, V., Bocquet, M., Saunier, O., and Mathieu, A.: Estimation of errors in the inverse modelling of accidental release of atmospheric pollutant: Application to the reconstruction of the cesium-137 and iodine-131 source terms from the Fukushima Daiichi power plant, J. Geophys. Res., 117, D05122, doi:10.1029/2011JD016932, 2012.

World Health Organization (WHO): Health effects of the Chernobyl accident and special health care programmes, edited by: Bennett, B., Repacholi, M., and Carr, Z., WHO, Geneva, 2006. 